\title{
Modeling the Arm II Core in MicroCap IV
}

\author{
A. C. Dalton
}

November 1996

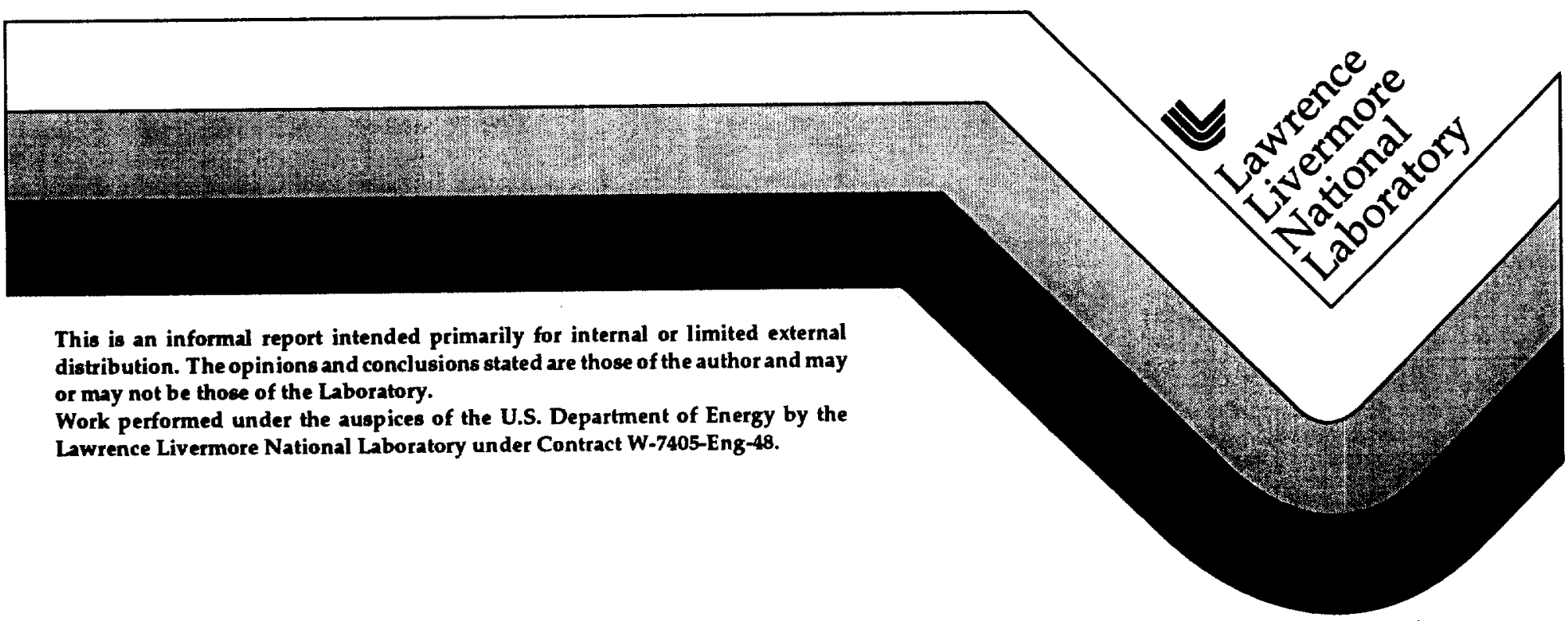




\section{DSCLADMER}

Thib document wro prepared as an socount of wotk sponsored by an agency of the United States Government. Neither the United States Covernment nor the University of California nor any of their employees, makes any warranty, express or implled, or asoumes any logel liability or responsibility for the sccuracy, completeness, or uefulness of any information, apparatus, product, or process discloeed or represents that its use would not tafringe privately owned rights. Refenence herein to any specific commendal product, process, or service by trade name, trademark, manufecturer, or otherwise, does not neceesarily conattute or imply its endorsenent, recoenmendation, or favoring by the United States Government or the University of California. The views and opinions of authors expressed herein do not necessarly state or reflect those of the United States Government or the University of California, and shall not be used for advertining or product endorsement purposes.

This report has been reproduced directly from the beet avilable copy.

\section{Available to DOE and DOE contractors from the Office of Scientific and Technical Information P.O. Box 62, Ouk Ridge, TN 37831}

Prices avellable from (615) 576-8401, FTS 626-8401

Available to the public from the National Technical Information Service

U.S. Depertment of Commerce 5285 Port Royal Rd., Springfield, VA 22161 


\title{
Modeling the Arm II Core in MicroCap IV \\ Andrew C Dalton
}

\begin{abstract}
This paper reports on how an electrical model for the core of the Arm II machine was created and how to use this model. We wanted to get a model for the electrical characteristics of the ARM II core, in order to simulate this machine and to assist in the design of a future machine. We wanted this model to be able to simulate saturation, variable loss, and reset. Using the Hodgdon model and the circuit analysis program MicroCap IV, this was accomplished. This paper is written in such a way as to allow someone not familiar with the project to understand it.
\end{abstract}

\section{B-H Loops}

I will first describe how a B-H loop "works", since this whole paper will be about trying to model a B-H loop. This is what a typical B-H loop for a ferromagnetic material looks like:

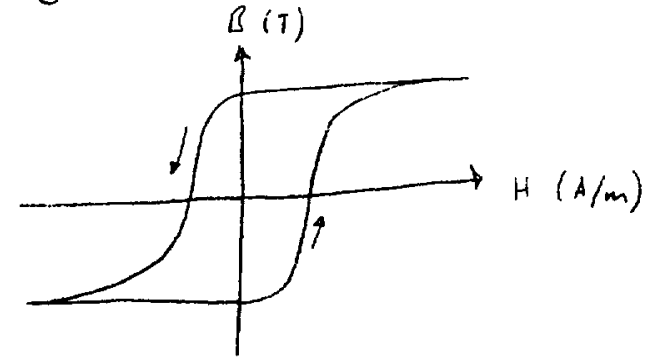

An air core solenoid has a B-H curve that looks like this:

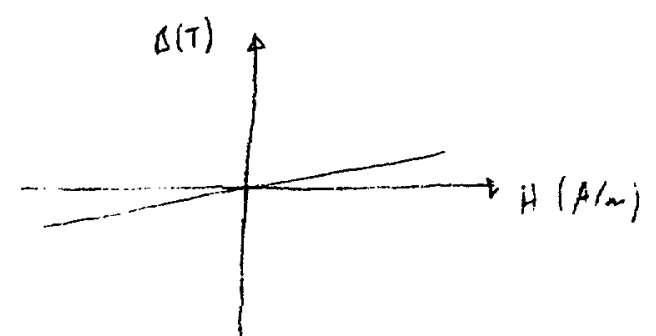


The slope of this line will always be the same. The steeper the slope of the line, the greater the inductance. Note that $B=0$ when $H=0$ for this line. This shows that when there is no current flowing in an air core solenoid, there is no magnetic field, where as in a ferromagnetic material, when there is no current flowing, there is usually a remnant field.

The B-H curve for a ferromagnetic material has two regions, one with a steep slope and one with a shallow slope. When a ferromagnetic material is added to a solenoid, it has the effect of making the inductance many time greater than the inductance would be in an air core solenoid (this is in the steep section). However; the metal can become saturated, which means from an electrical stand point that it's inductance become very small, and looks like an aircore solenoid then. It becomes a short circuit essentially (this is the flat section).

In a solenoid, $H$ is proportional to current, and voltage is proportional to the time rate of change of the magnetic field $(\mathrm{dB} / \mathrm{dt})$. You can see that in the steep region, there is little current. In this region, B usually changes quickly, causing a big voltage. This is equivalent to a big inductance. In the saturation region, a lot of current can flow, but the B field cannot change that much, hence there can only be a little voltage. This is equivalent to a low impedance.

The last point to make about a B-H loop is that it takes energy to switch the magnetization state from one value to another. The energy absorbed in one cycle is proportional to the area of the loop. 


$$
\begin{array}{ll}
B \cdot H=T \times A / m=\frac{\mathrm{kg}}{A \mathrm{~s}^{2}} \times \frac{A}{\mathrm{~m}}=\frac{\mathrm{Kg}}{\mathrm{ms^{2 }}} \\
\text { energy }=J=\frac{m^{2} \mathrm{~kg}}{\mathrm{~s}^{2}} & \text { volume }=\mathrm{m}^{3}
\end{array}
$$

So Area of B-H loop * volume of magnetic material $=\frac{\mathrm{kg}}{m s^{2}} \times m^{3}=\frac{m^{2} \mathrm{~kg}}{\mathrm{~s}^{2}}=\mathrm{J}$

So there is more loss in a B-H loop with a large area than a B-H loop with a small area, for a given volume of magnetic material.

The area inside the $\mathrm{B}-\mathrm{H}$ loop increases as the magnetization rate increases. This means that the more quickly a solenoid is magnetized, the more energy will be lost. [1]
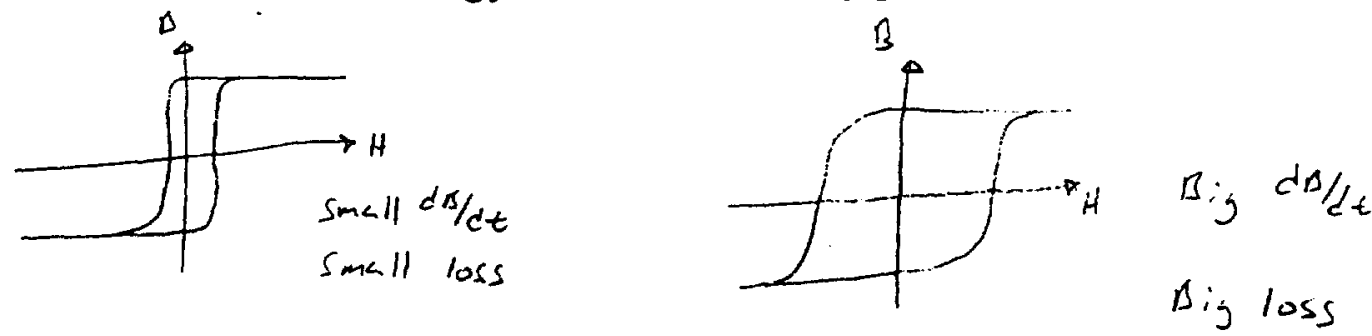

ARM II Machine

The Arm II machine is a high voltage modulator which releases the energy stored in capacitors through a solenoid, creating a strong magnetic field. To prevent the core from saturating on the next pulse, it is necessary to reset the core back to its original magnetization state. This is done by a separate set of capacitors, that try to run current the opposite way through the solenoid to reset it. [2] A simple circuit model of this device:

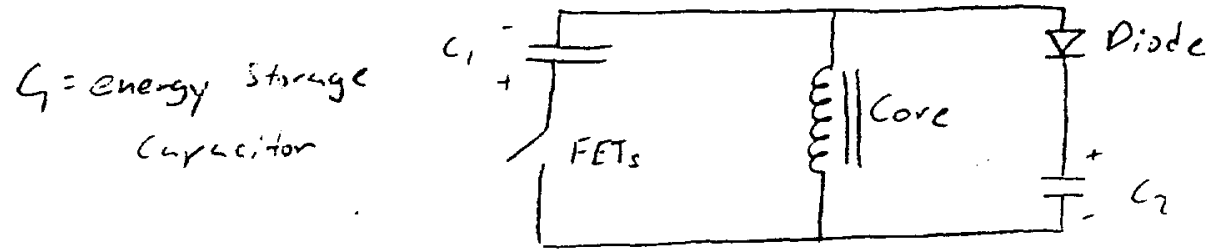


A good electrical model of the core was needed, in order to predict the modulator's flux behavior, and to aid in the design of future modulators. It was desired that this model

1. have the correct saturation point

2. reset to the original state

3. make minor loops

4. have the correct loss for a given rate of magnetization.

Faced with a similar problem and a similar set of criterion, Jan Zentler chose the Hodgdon model of a B-H loop, and so did I. [3]

\section{Hodgdon Model}

Marion Hodgdon along with Bernard Coleman came up with a model for a B-H loop. [4-7] This model is not based on the physical theory of magnetization. It is just an equation that when properly restricted, can closely mimic the behavior of a B-H loop. The equation is

$$
\dot{H}=\alpha|\dot{B}|[f(B)-H]+\dot{B} g(B)
$$

In a couple of papers, Hodgdon put restrictions on the functions $f(B)$ and $g(B)$, and also offered suggestions for their form and ways to determine them. The constant a affects the shape of the loop.

To use this equation in a circuit modeling program, Jan Zentler rewrote the equation as

$$
\bar{B}=\frac{\dot{H}-\alpha|\dot{b}|(f(r)-H)}{g(B, \dot{B})}
$$


and used analog circuit elements to model it. This model is

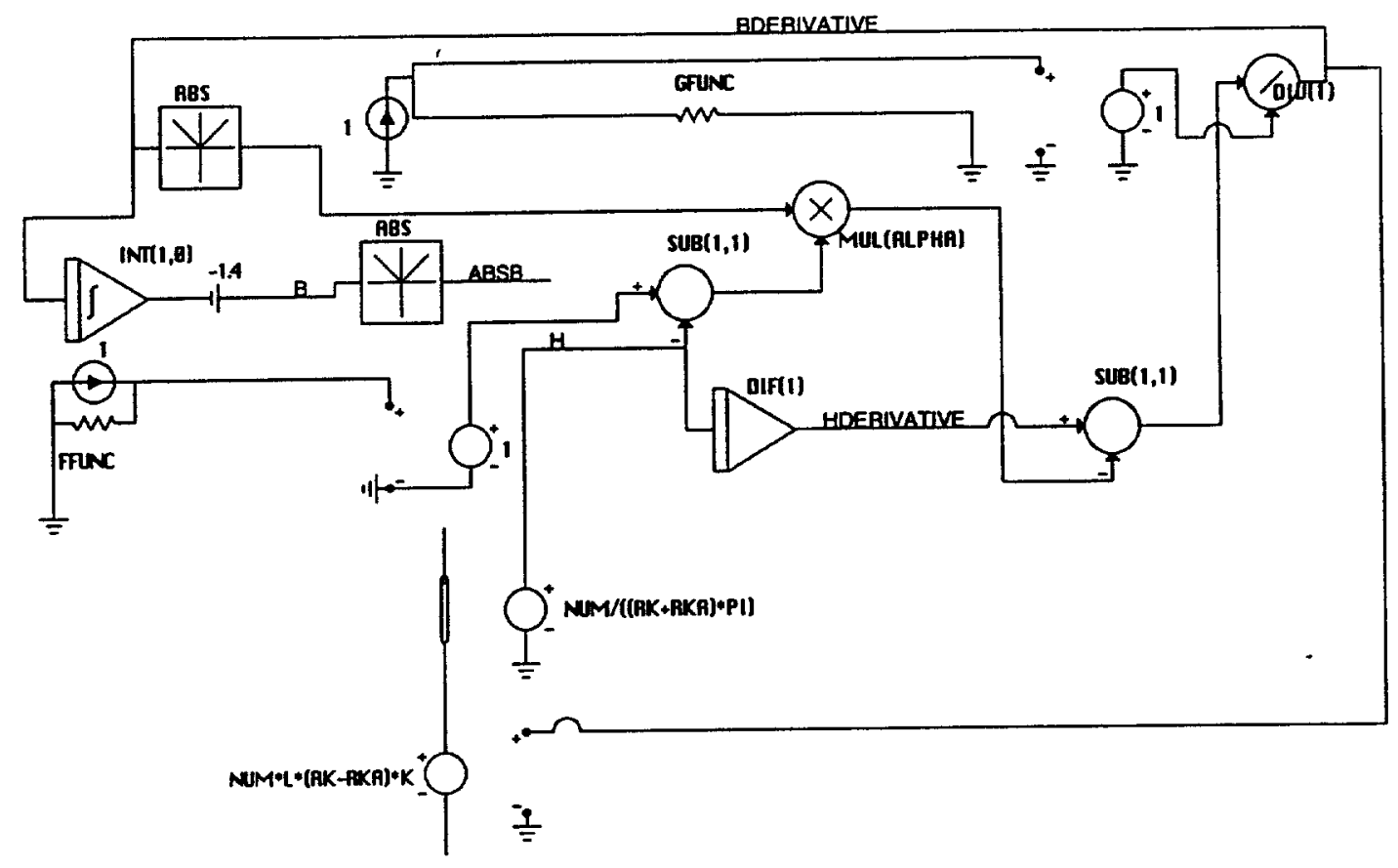

For a circular toroid,

$\mathrm{L}=$ axial length of core

$\mathrm{r}_{\mathrm{m}}=$ outside radius

ro $=$ inside radius

$\mathrm{N}=$ number of turns

$\mathrm{k}=$ core stacking factor

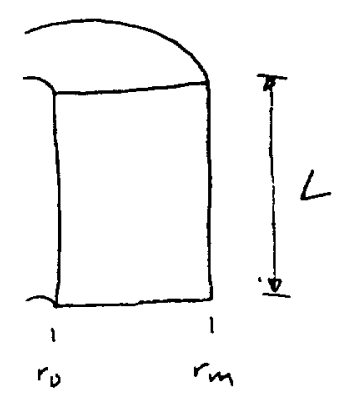

The input to the model is $\mathrm{H}$ which is calculated from current as

$$
H=\frac{N_{i}}{\left(r_{m}+r_{0}\right) \pi}
$$


The output of the model is the voltage the core will have across it, and is calculated from $\mathrm{dB} / \mathrm{dt}$ as

$$
V=N L\left(r_{m}-r_{0}\right) R \dot{B}
$$

In one of Hodgdon's papers, she offers two forms of $f(B)$ and $\mathrm{g}(\mathrm{B})$ that meet her criterion and simulate a B-H loop well. The simplest one, with $f(B)$ and $g(B)$ piece-wise linear functions, is the most robust, and easily calculable, and is sufficient for our needs. .

$$
\begin{aligned}
& f(B)= \begin{cases}D_{1}\left(B+B_{C L}\right)-D_{2} B_{C L} & B<-B_{C L} \\
D_{2} B & |B| \leq D_{C L} \\
D_{1}\left(B-B_{C L}\right)-D_{2} B_{C L} & B>B_{C L} .\end{cases} \\
& g(B)=\left(1+D_{3}\right) D_{2} \quad|\Delta| \leq B_{C L} \\
& \begin{array}{ll}
-P_{1} & |n|>B_{C L}
\end{array}
\end{aligned}
$$

The constants D1, D2, D3 can be determined from a B-H loop.

$$
\begin{aligned}
& D_{1}=1 / \mu_{C L} \\
& D_{2}=\frac{H_{C}}{B_{r}} \frac{\left[1-e^{-\alpha\left(\Delta_{C L}-\Delta_{r}\right)}\right]}{\left[1-e^{\left.-\alpha B_{C L}\right]}\right.} . \\
& D_{1}=\frac{\alpha \Delta_{r}}{\left[1-e^{-\lambda\left(B_{C L}-B_{r}\right)}\right]}
\end{aligned}
$$

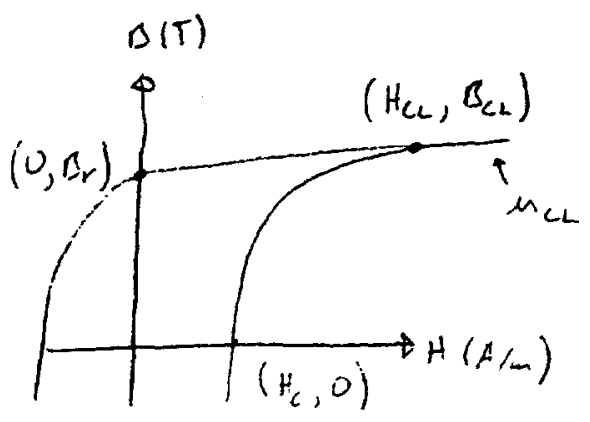

If D1, D2, D3, are calculated in this way, the loop will pass through the points $\mathrm{Hc}, \mathrm{Br}$, and $\mathrm{Bcl}$, and will have a slope of $\mathrm{mcl}$ in the saturation region.

This form of the model will not have a rate dependent loss. Whatever $\mathrm{dB} / \mathrm{dt}$ is, there will always be the same loss with the model as it is now. To make the loss (and hence the $\mathrm{B}-\mathrm{H}$ area) rate dependent, Hodgdon proposes adding a function $\mathrm{c}(\mathrm{dB} / \mathrm{dt})$ to $\mathrm{g}(\mathrm{B})$. 


$$
g(B, \dot{B})=\left\{\begin{array}{cl}
\left(1+c(\dot{B}) D_{3}\right) D_{2} & |B| \leq B_{C L} \\
D_{1} & |B|>B_{C L}
\end{array}\right.
$$

The function $\mathrm{c}(\mathrm{dB} / \mathrm{dt})$ will be determined from published loss data. At the $\mathrm{dB} / \mathrm{dt}$ at which the data for the $\mathrm{B}-\mathrm{H}$ curve is taken, $c(d B / d t)=1 . \quad c(d B / d t)$ is a function that is equal to the loss at the current $\mathrm{dB} / \mathrm{dt}$ over the loss at which he B-H loop data was taken. (Actually, the B-H loop data should be taken at DC, according to Hodgdon, but MicroCap IV would not accept these numbers.)

\section{Experimental B-H loop data}

In order to get reasonable numbers for the Hodgdon equation, we need B-H loop data. This can be obtained either experimentally with a core tester, or this information can be found in the published data. We will look at both sources of data and compare them.

The ultimate goal of using the core tester is to simulate the RLC circuit of the core tester with the Hodgdon model for the core, and see if the simulation comes close to the experimental results. We will first determine the RLC circuit parameters of the core tester without the core, and then we will put the core back in and use the machine to get B-H data for the exact type of material used in the core of the ArmII machine (Metglas 2605SC).

There are three parts to the machine: the capacitor, the ignitron, and the core. The ignitron is a switching device. The core is made in such a way that the Metglas can be removed from the solenoid, leaving just an air core solenoid. 
This is the way the core tester is used. The capacitor is charged up to the desired voltage (anywhere from $0-15 \mathrm{kV}$ ), and then the ignitron is fired. This closes the circuit, and the voltage and current are displayed on an oscilloscope. This is the circuit diagram.

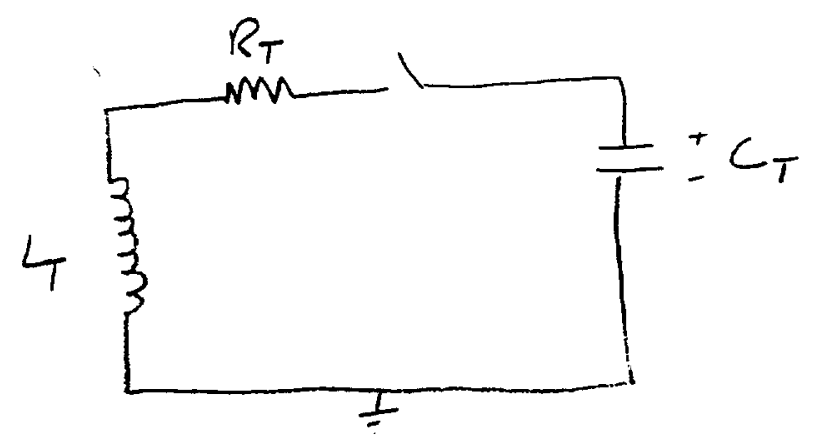

To measure the current, a current probe was put around the wire coming out of the solenoid. Current probes come already calibrated from the manufacturer. A Tektronix voltage probe \#P6015 was used to measure the voltage. These voltage probes must be calibrated to a known pulse source. There is a box on the oscilloscope that can be used to calibrate the probe. A mercury pulser was used as a known pulse source. This is the set-up.

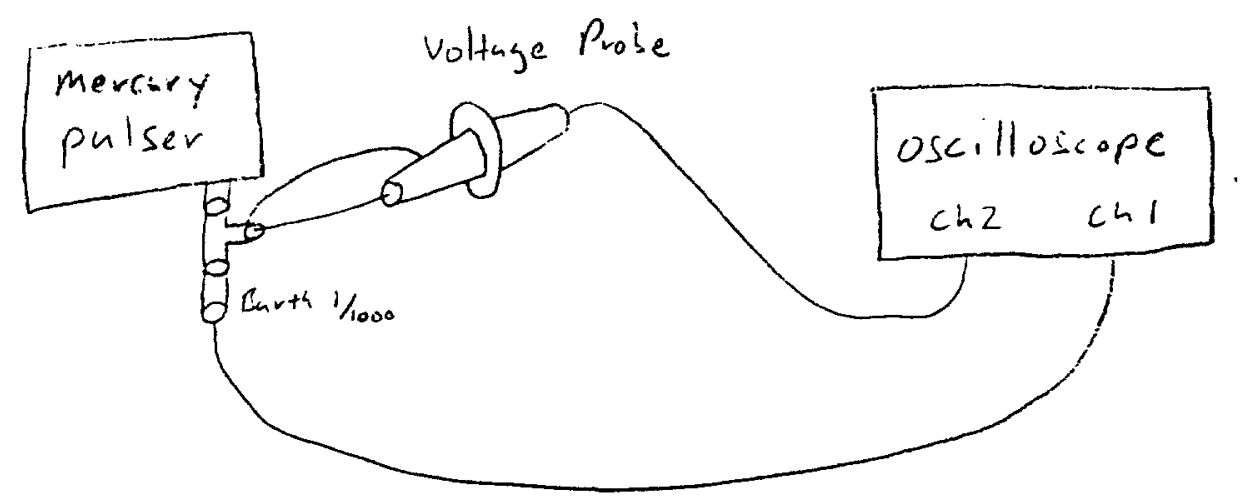

We played with the probe calibration screws until we got the two traces to lie on top of one another. 


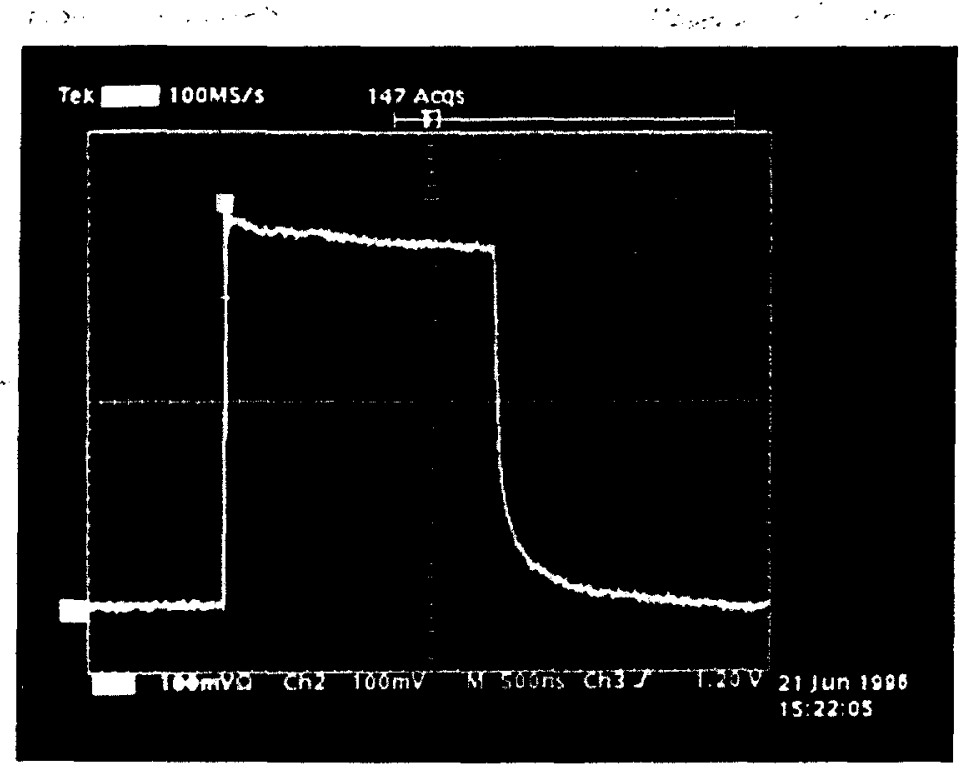

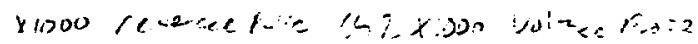

We also had to ensure that the delay in the current monitor cable was the same as the delay in the voltage probe cable. If the delay was different, then this would change the phase between the voltage and the current, and the calculations for the circuit parameters would be off. To ensure the delay was the same in both cables, we used the TDR. This machine displays how long it takes a pulse to travel to the end of a cable and bounce back. Once the delay for the voltage probe was determined, a bit of additional cable was added to the current probe cable to make the delay the same.

There were two other things we had to do to the instrumentation. Because we were going to be measuring kiloamps, we had to attenuate the current probe signal by 100 . And in order to get rid of the high frequency noise, we wrapped the cables of the probes a couple time around some ferrite toroids.

Now we were happy that what we were seeing on the oscilloscope was real. We then determined what the circuit parameters of the core tester were without the core. 


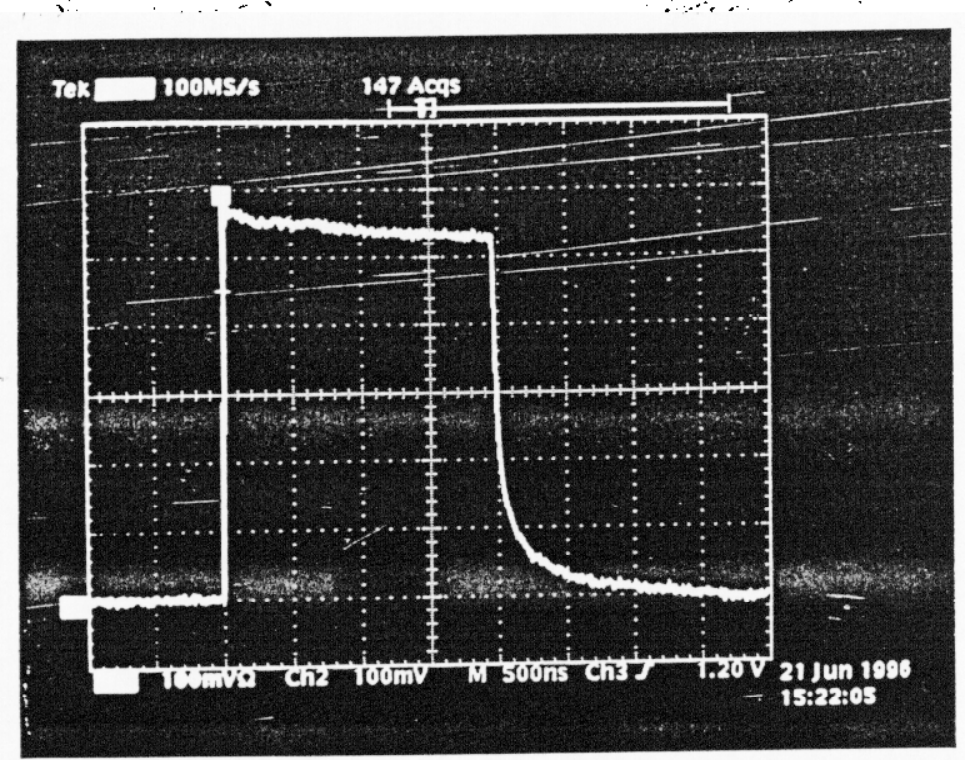

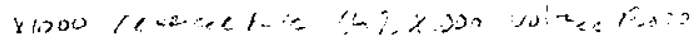

We also had to ensure that the delay in the current monitor cable was the same as the delay in the voltage probe cable. If the delay was different, then this would change the phase between the voltage and the current, and the calculations for the circuit parameters would be off. To ensure the delay was the same in both cables, we used the TDR. This machine displays how long it takes a pulse to travel to the end of a cable and bounce back. Once the delay for the voltage probe was determined, a bit of additional cable was added to the current probe cable to make the delay the same.

There were two other things we had to do to the instrumentation. Because we were going to be measuring kiloamps, we had to attenuate the current probe signal by 100 . And in order to get rid of the high frequency noise, we wrapped the cables of the probes a couple time around some ferrite toroids.

Now we were happy that what we were seeing on the oscilloscope was real. We then determined what the circuit parameters of the core tester were without the core. 
By looking at the decay and the period of oscillations, it is possible to determine the total capacitance, inductance, and resistance of the circuit.

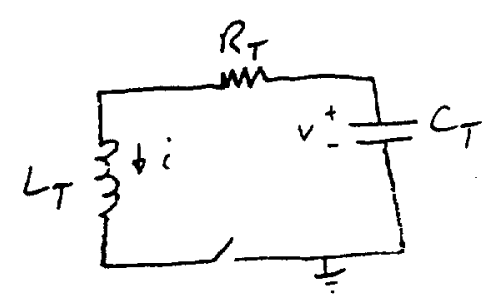

$$
\begin{aligned}
& i=\frac{V}{\omega L_{T}} e^{-\alpha t} \sin \omega t \\
& \alpha=\frac{R_{-}}{2 L_{T}} \\
& \omega=\sqrt{\frac{1}{L_{T} C_{T}}-\frac{R_{T}^{2}}{4 L_{T}^{2}}}
\end{aligned}
$$

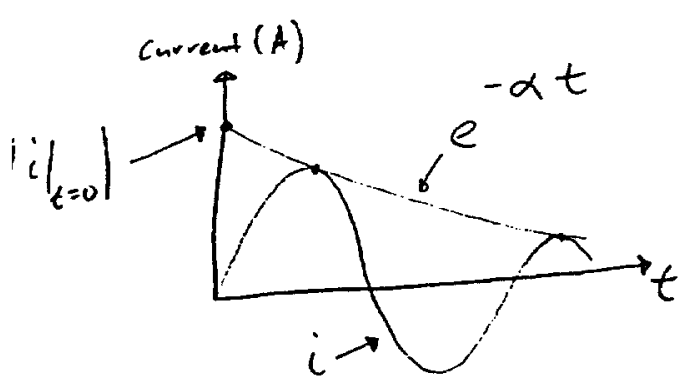

$$
L_{T}=\frac{V}{\omega|i|_{t=0} \mid}
$$

To solve for CT, LT, and RT, you need to know $V t=0, w$ and alpha (not the a of the Hodgdon equation). By measuring the peaks of the current, it is possible to put this information in an equation solver program and determine alpha and the magnitude of $i$.

Using two shots, at $\mathrm{V}=4 \mathrm{kV}$ and $\mathrm{V}=6.5 \mathrm{kV}$, I came up with values for RT, LT, and CT, and got very good agreement between the two. I averaged the two results together to get the final values. Compare a simulation of this equivalent circuit to the actual data taken. 

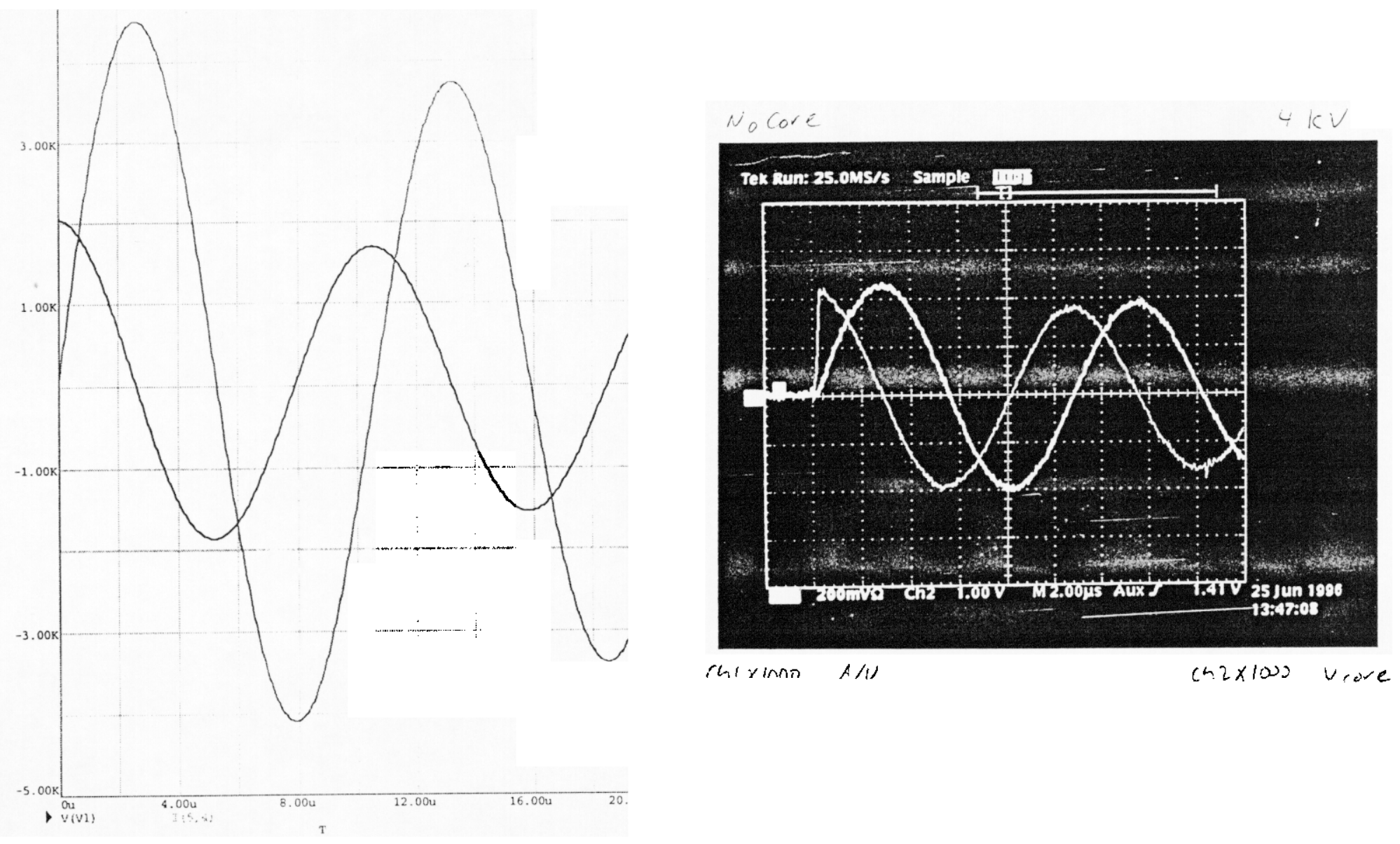

Now we will put the metglas core in the solenoid and find out what the B-H curve of it looks like. Instead of measuring the voltage across the core, one turn of wire was wound very tightly around the metglas, and the voltage across thus loop was measured. This way a lot of the leakage inductance voltage is not measured. If we multiply the current by 4.08 , this will be $\mathrm{H}$. And if we multiply the one turn voltage by blah, this will be 274.7 .

In the high inductance region, the voltage is nearly constant. So to find $B$ in this area, we first pick a spot to be equal to zero. The $B$ for any other spot in this area is equal to the difference in time between the zero spot and the spot in question times $\mathrm{dB} / \mathrm{dt}$. A set of B-H data can be obtained this way. 


$$
C(d 8 / d t) \equiv .24458+1.9898 \times 10^{-6} *(d 8 / d t)
$$

Conclusion

The Hodgdon model was chosen to simulate the electrical characteristics of the type of material used in the ARMII core. Values for this model were obtained by experimentation by myself and from published experimental data by Carl Smith. Smith's data was more useful, and the final Hodgdon model is based on this information.

\section{Discussion of Models and Experiments}

I could not find a quantitative way to determine what the constant a should be. In Hodgdon's papers, all she ever says about the constant $\mathrm{a}$ is that it is positive. Zentler gives a little more information. He writes that "the constant a determines the shape of the minor B-H loops. A large value of a will bend minor loop trajectories parallel to the $\mathrm{H}$ axis." It also affects the major loop (see the examples).

Since this is the case, the constant a is chosen somewhat arbitrarily, based on the resemblance of the minor loop generated by the computer to the actual minor loop of the core. 
Using this data, we came up with values for the Hodgdon

$$
\begin{aligned}
& \text { equations. } \quad B_{C L}=1.36 \quad B_{r}=1.208 \quad H_{C}=90 \quad \mu_{C L} \cong 7 \times 10^{-5} \\
& \alpha=j \\
& D_{1}=14000 \quad D_{2}=27.75 \quad D_{2}=9.897
\end{aligned}
$$

The other way to get values for the Hodgdon equations is to used published B-H data. Carl Smith published a B-H curve for Metglas 2605SC at nearly the same $\mathrm{dB} / \mathrm{dt}$ we used and the same thickness of tape. [8,9] Using this data, the vales are

$$
\begin{array}{cc}
B_{C L}=1.55 \quad D_{\sigma}=1.4 \quad H_{C}=75 \quad \mu_{C L} \simeq 7 \times 10^{-5} \\
\alpha=3 \\
\therefore \quad D_{1}=14000 \quad D_{2}=19.6 \quad D_{3}=11.59
\end{array}
$$

I decided to use the published data because there was loss data for a range of $d B / d t s$. Using this information, I can add the $c(d B / d t)$ function to $g(B)$ and get a loss dependent upon rate of magnetization.

First, I had to calculate what loss the Hodgdon model was giving me with the equations I had so far. Since this was different from the published loss, I modified Hc to give the loop about the right area for this $\mathrm{dB} / \mathrm{dt}$. It is $\mathrm{OK}$ to do this, because we are most concerned with the correct saturation point and the correct loss. The small variation in current in the high inductance region is secondary to these two conditions. A value of $125 \mathrm{~A} / \mathrm{m}$ was determined to have about the right loss. Using the Smith data, $c(d B / d t)$ was determined. 
I have thought of one way that may be used to pick the constant a. Pick the constant a so the slope of the curve of the simulation at the $B=0$ axis is the same as the actual slope at that

Using this data, we came up with values for the Hodgdon

$$
\begin{gathered}
\text { equations. } \begin{array}{c}
B_{C L}=1.36 \quad \Delta_{r}=1.208 \\
\alpha=5
\end{array} \quad H_{C}=90 \quad \mu_{C L} \equiv 7 \times 10^{-1} \\
\therefore \quad D_{1}=14000 \quad D_{2}=27.75 \quad D_{3}=9.897
\end{gathered}
$$

The other way to get values for the Hodgdon equations is to used published B-H data. Carl Smith published a B-H curve for Metglas 2605SC at nearly the same $\mathrm{dB} / \mathrm{dt}$ we used and the same thickness of tape. [8,9] Using this data, the vales are

$$
\begin{array}{cc}
B_{C L}=1.55 \quad D_{r}=1.4 \quad H_{C}=75 \quad \mu_{C L} \simeq 7 \times 10^{-5} \\
\alpha=3 \\
\therefore \quad D_{1}=14000 \quad D_{2}=19.6 \quad D_{3}=11.59
\end{array}
$$

I decided to use the published data because there was loss data for a range of $d B / d t s$. Using this information, I can add the $c(d B / d t)$ function to $g(B)$ and get a loss dependent upon rate of magnetization.

First, I had to calculate what loss the Hodgdon model was giving me with the equations I had so far. Since this was different from the published loss, I modified $\mathrm{Hc}$ to give the loop about the right area for this $\mathrm{dB} / \mathrm{dt}$. It is $\mathrm{OK}$ to do this, because we are most concerned with the correct saturation point and the correct loss. The small variation in current in the high inductance region is secondary 
I have thought of one way that may be used to pick the constant a. Pick the constant a so the slope of the curve of the simulation at the $\mathrm{B}=0$ axis is the same as the actual slope at that point. This would work OK with my experimental data, but with the published data, the slope is negative at this point.

\section{Examples}

Here are some examples of what happens as a, mcl, $\mathrm{Hc}, \mathrm{Br}, \mathrm{Bcl}$ are varied up and down. Only one variable was changed at a time, and the other variables stayed at their original values. The function $c(d B / d t)$ was not used for these simulations.

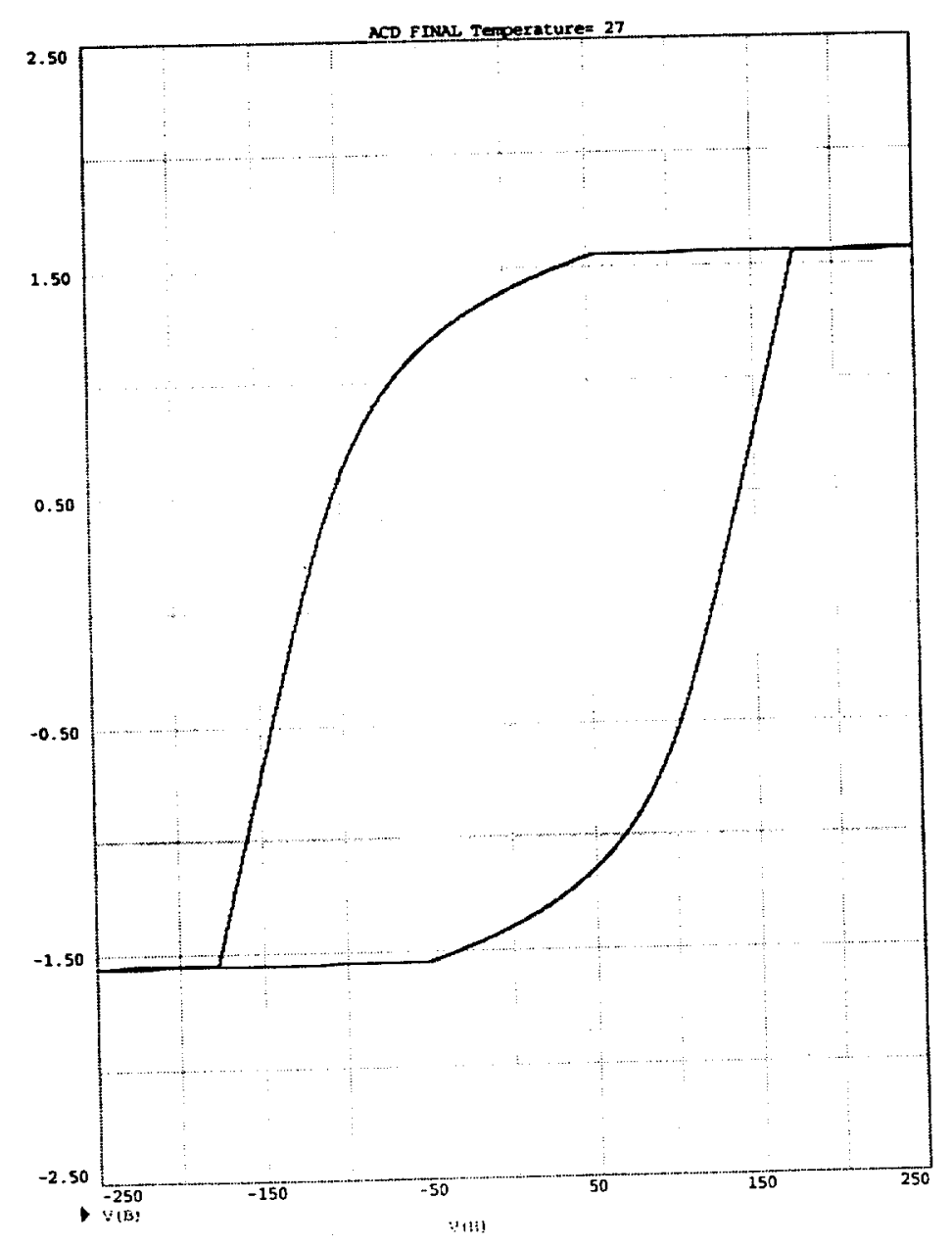

$$
\begin{aligned}
& \text { origina! } \\
& \alpha=I \\
& D_{V}=1 \cdot \\
& A_{C L}=1.5 \\
& H_{L}=12 ! \\
& n_{C L}=1 / 14000 \\
& D_{1}=14000 \\
& D_{2}=32.666977959 \\
& D_{3}=11.5903043208
\end{aligned}
$$



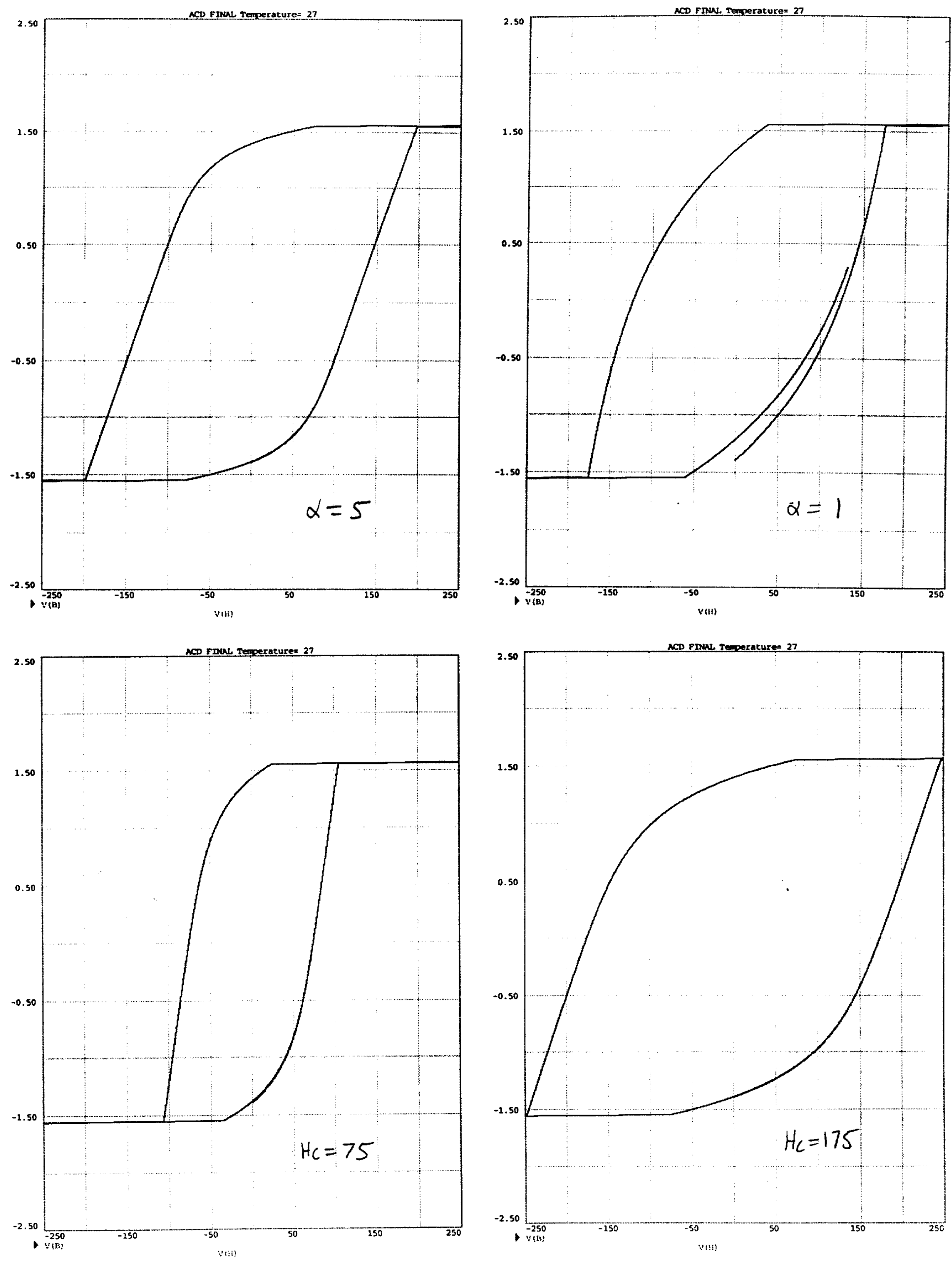

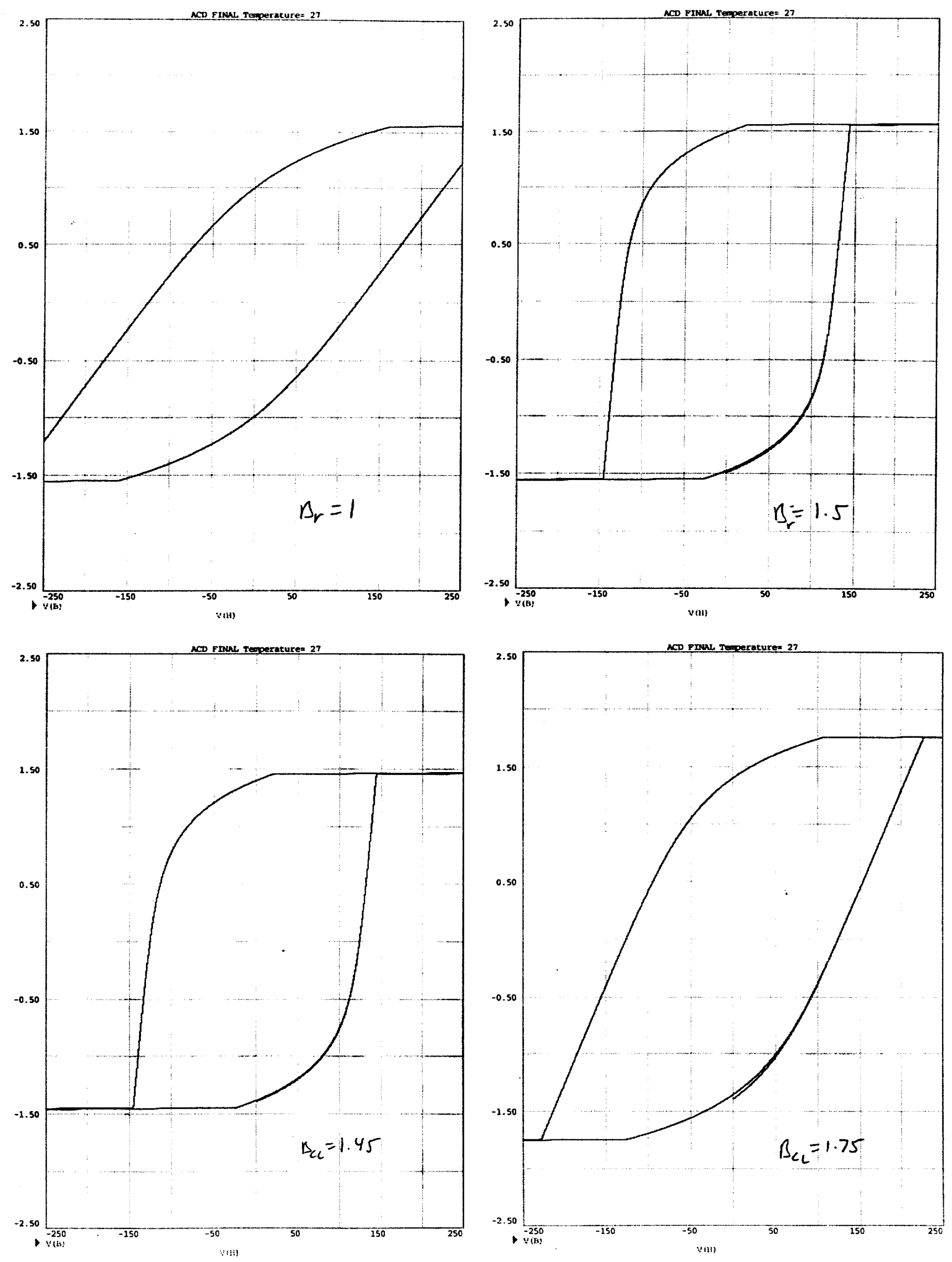
D1, D2, D3 are calculated from the previous variables. If any one of these is altered, it will affect D1, D2, and/or D3. But if you are not looking for a consistent model, and just want to see a different B$\mathrm{H}$ shape, you could just play with D1, D2, and D3.
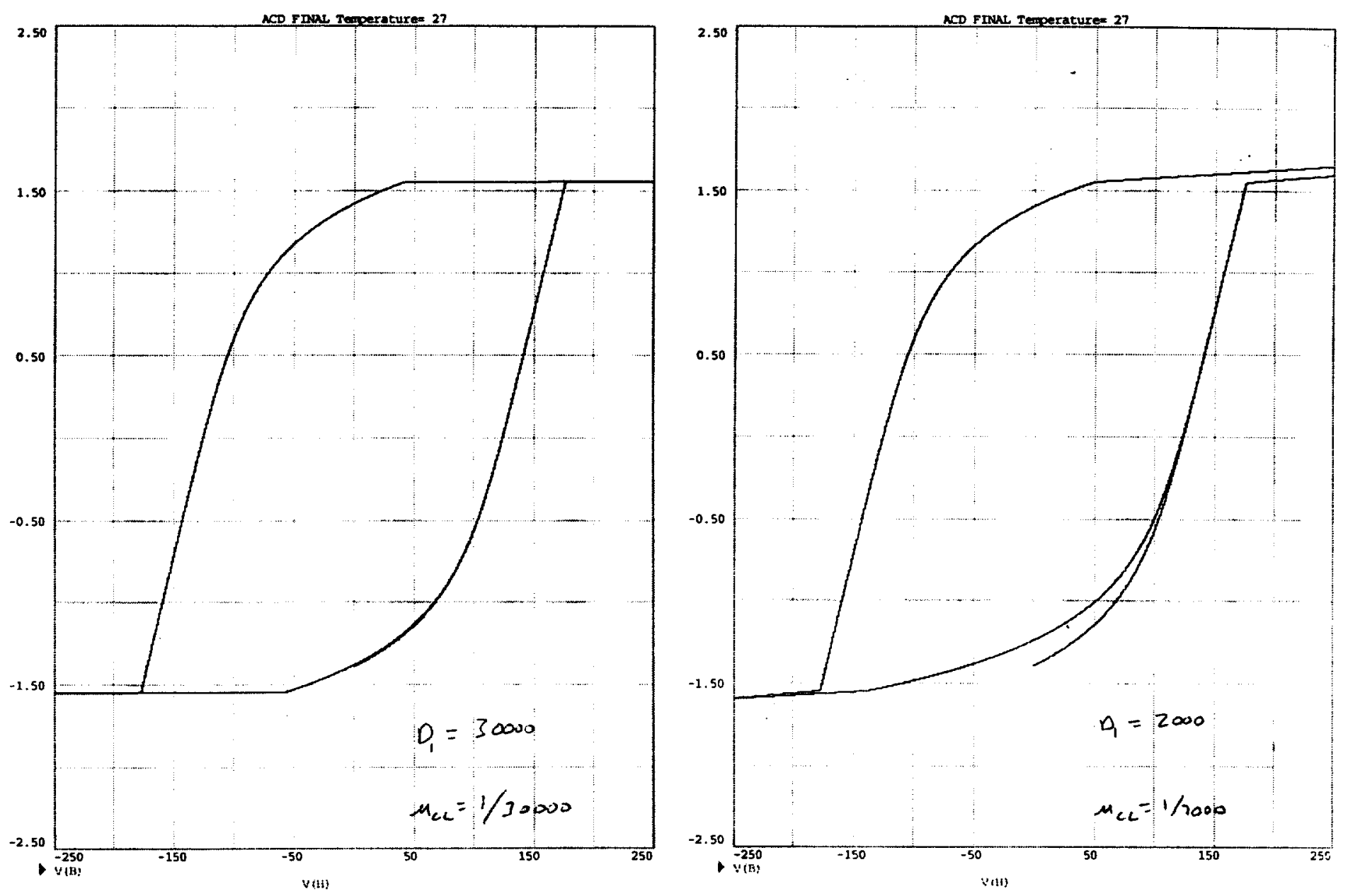

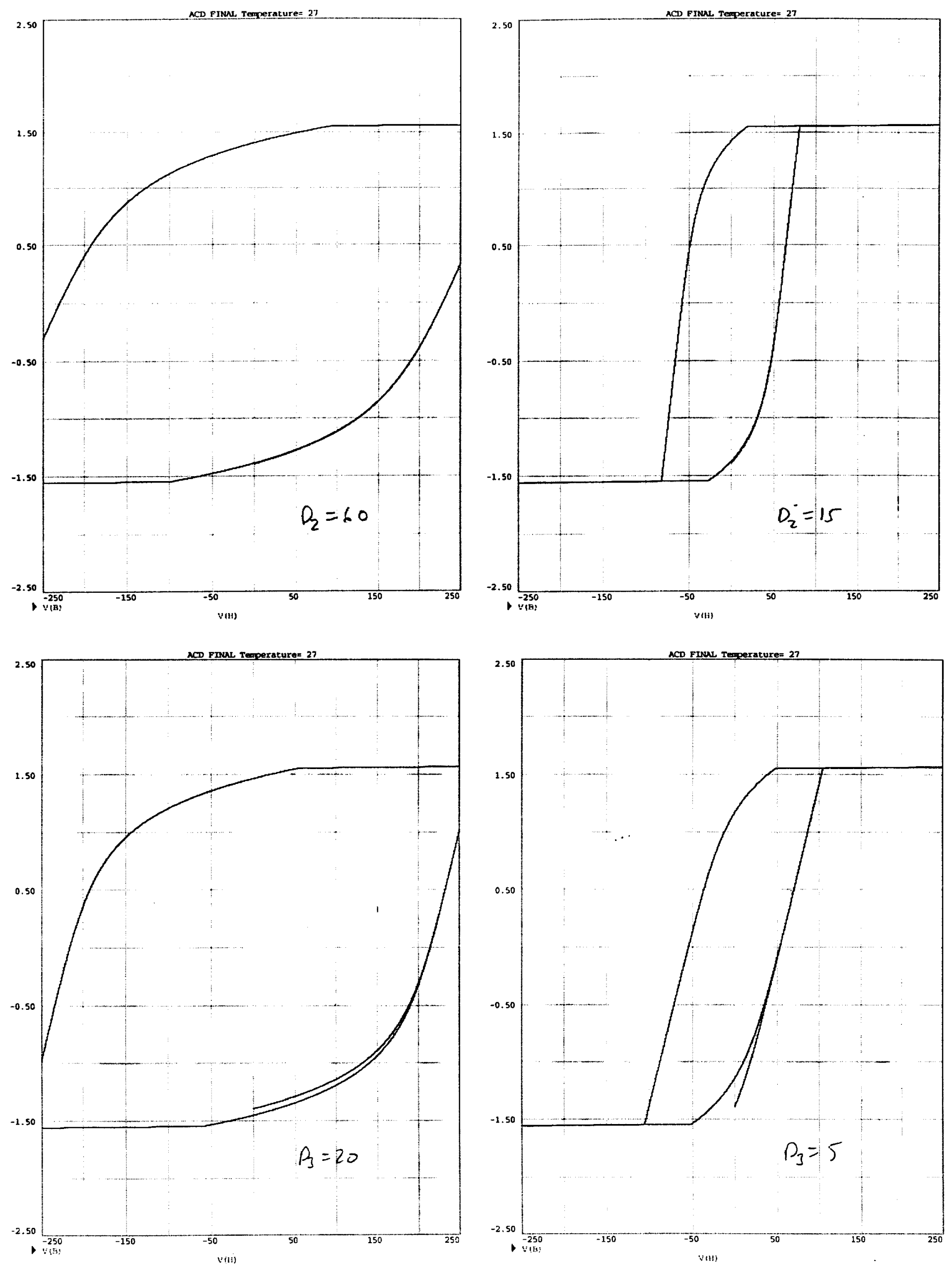
Examples of playing with initial B. Examples of the model in an RLC circuit with the $c(d B / d t)$ function.
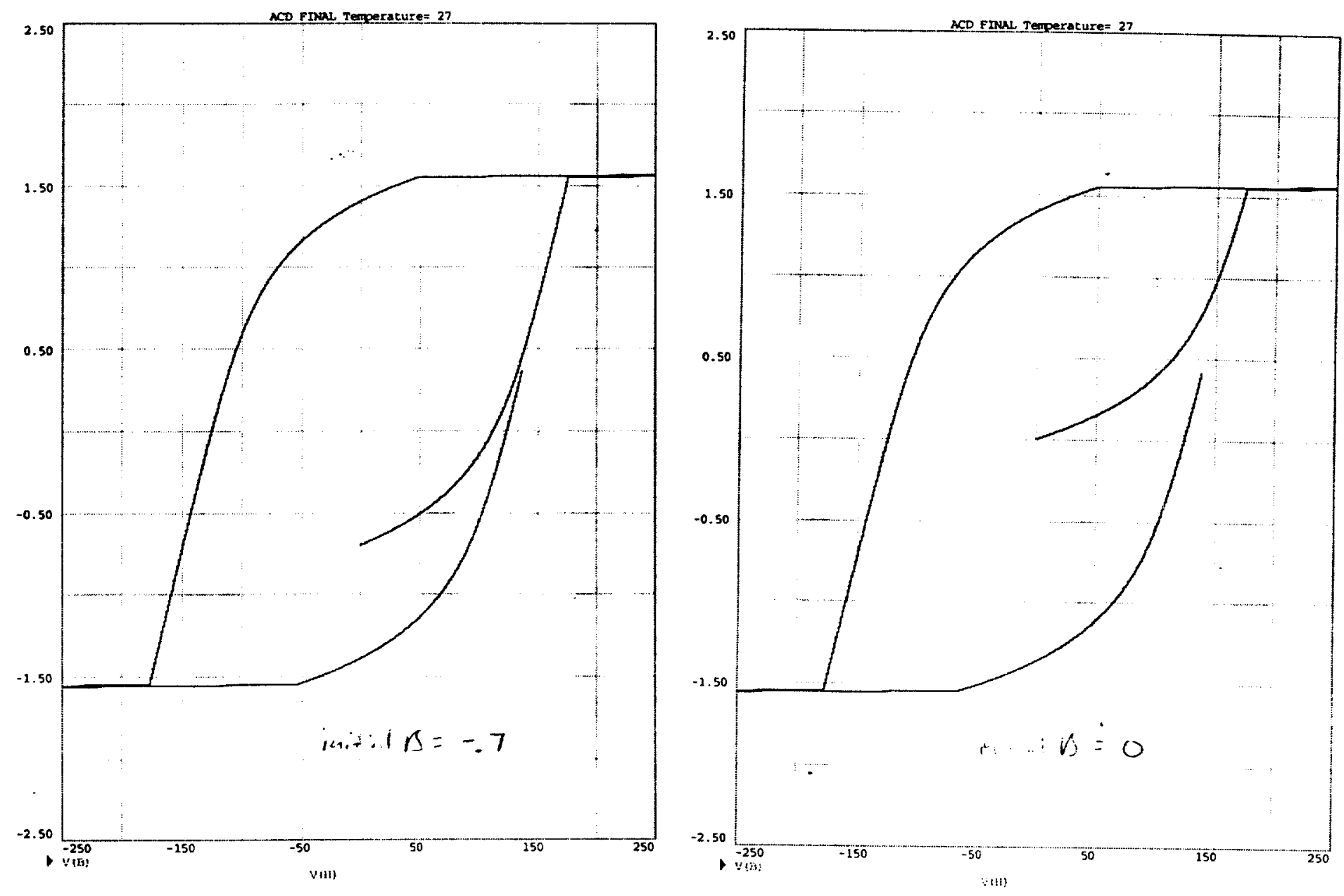


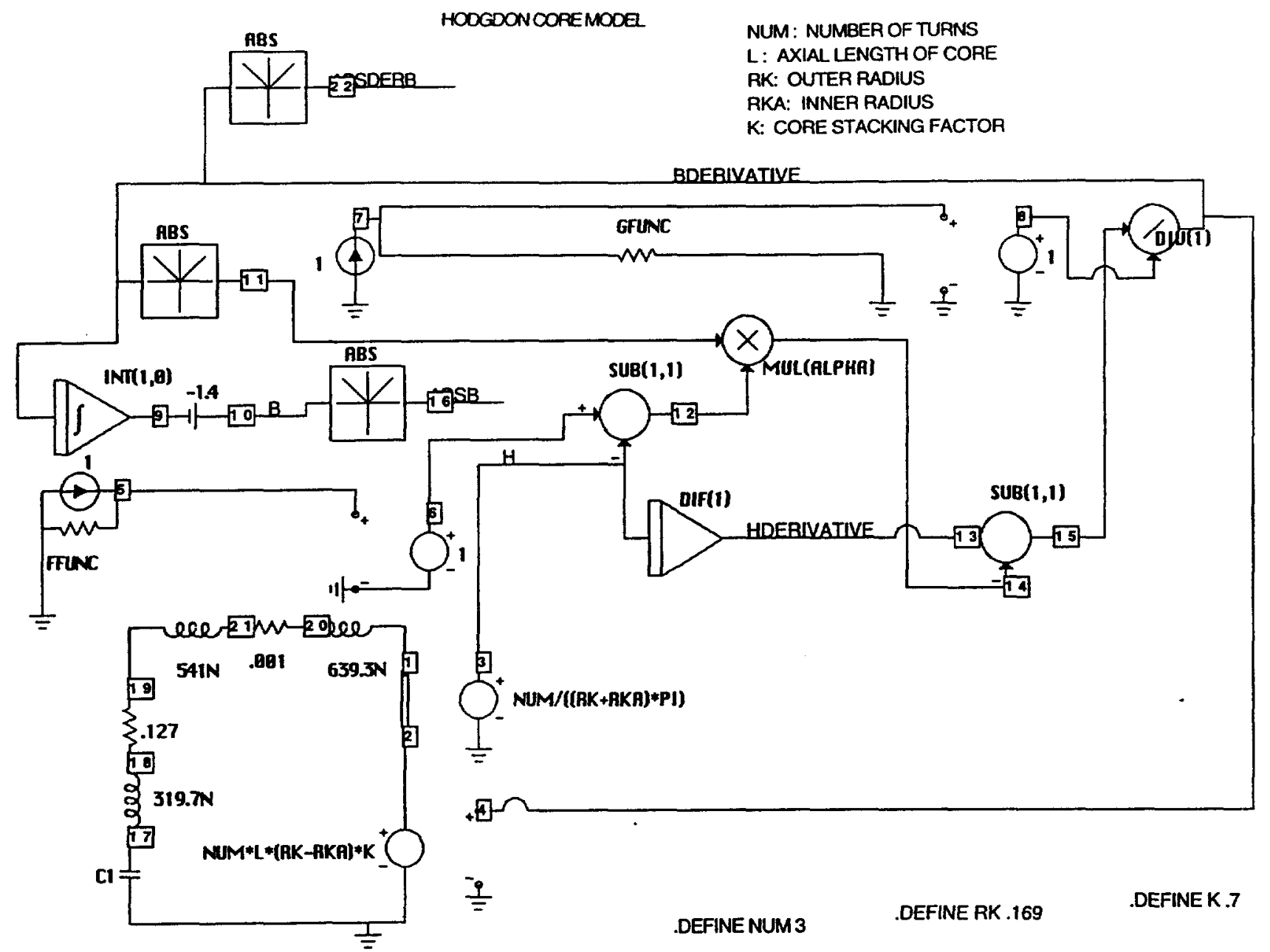

.DEFINE CI $2 U$ IC $6.5 \mathrm{KV}$

.DEFINE ALPHA 3

.DEFINE L .05

.DEFINE KA .065

THIS CIRCUIT CALCULATES H FROM I AND THEN CALCULATES THE

DERIVATIVE OF $B$. IT THEN CALCULATES $V$ FROM THE DERIVATIVE OF $B$.

.DEFINE FFUNC (D B*V(B)* $\left.(V(A B S B)<=1.55)+\left(D A^{*}(V(B)-1.55)+D B^{* 1.55}\right)^{*}(V(B)>1.55)+\left(D A^{*}(V(B)+1.55)-D^{*} 1.55\right)^{*}(V(B)<-1.55)\right)$

.DEFINE GFUNC $\left(\left(1+\left(.24458+1.9898 E-6^{*} V(A B S D E R B)\right)^{\circ} D C\right)^{*} D^{*}(V(A B S B)<=1.55)+D^{*}(V(A B S B)>1.55)\right)$

$$
(d \cdot d t)
$$

.DEFINE DA 14000

DEFINE EXP 2.71828182846

.DEFINE DB 32.666977959

DEFINE DC 11.5903043208

This simulation shows that $c(d v / d t)$

changes the area of the B-H loup. 
ACD HODGDON LINEAR RLC VAR LOSS Temperature $=27$
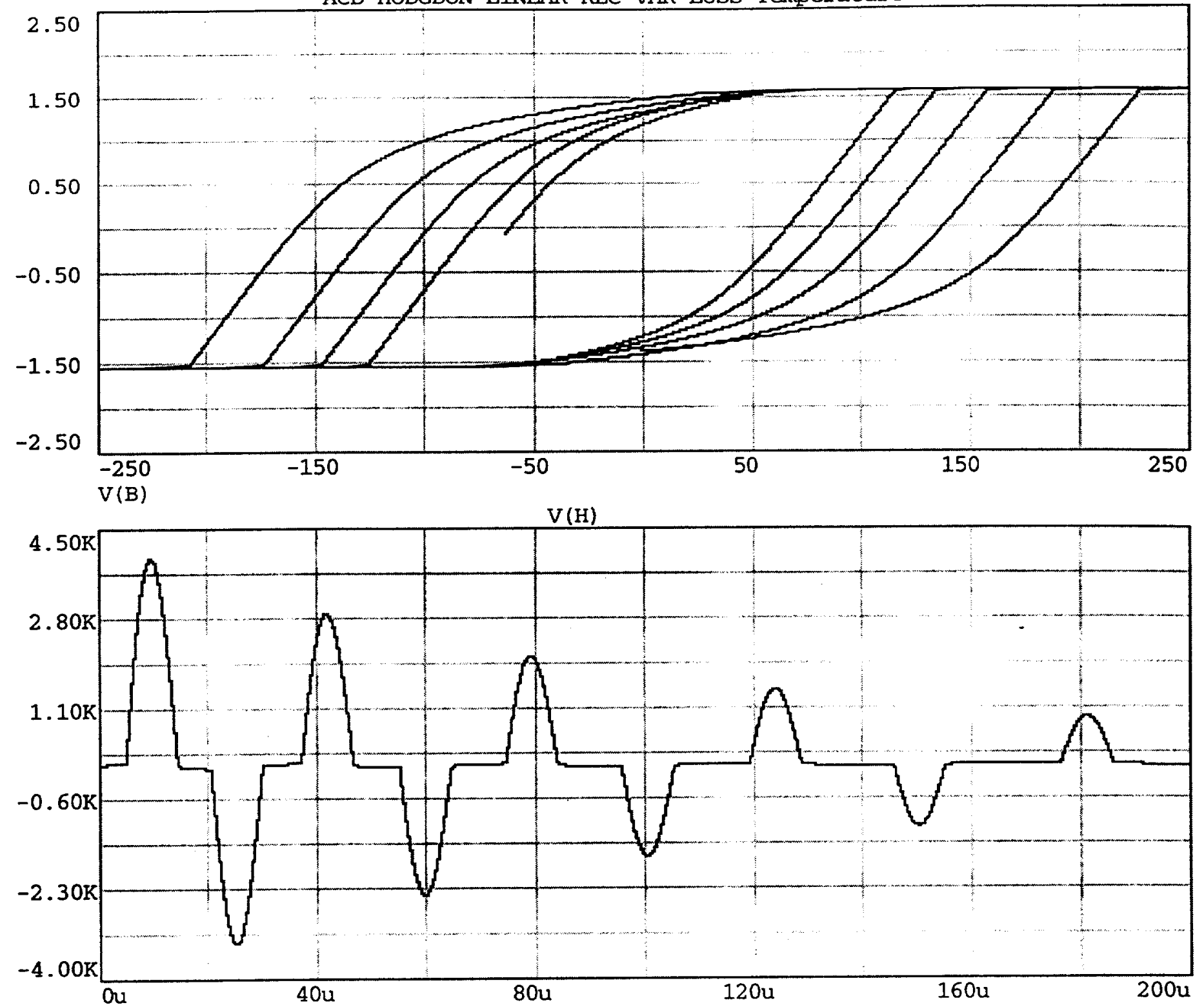

- I $(21,20)$

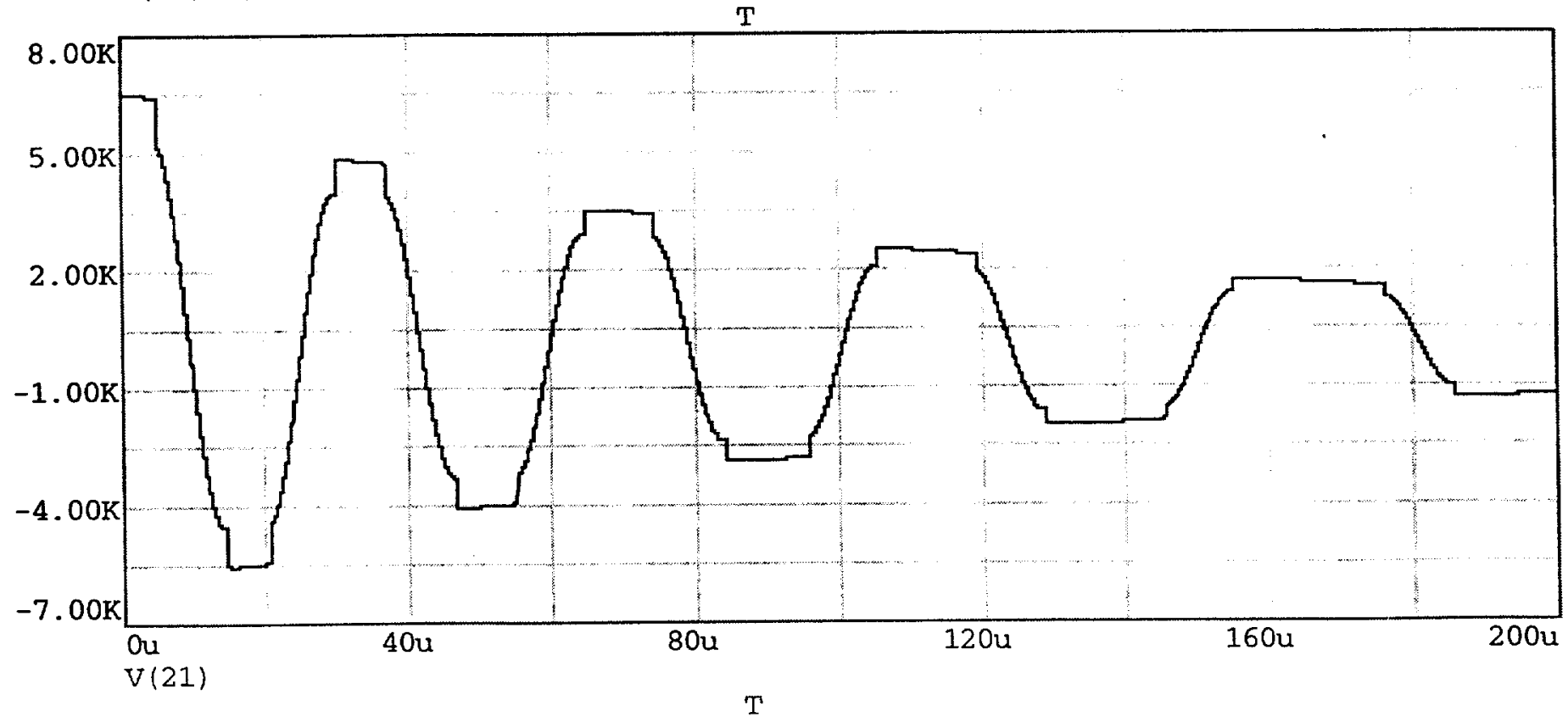




\section{MicroCap IV Section}

The analog circuit elements needed to implement the Hodgdon function were available as already installed macros in MCIV.

For the input $\mathrm{H}$, a current controlled voltage source was used. The controlling current is the current that goes through the turns around the solenoid. The current was multiplied by the appropriate value, and became $\mathrm{H}$ for the input. The output was a voltage controlled voltage source, with the controlling voltage being the $\mathrm{dB} / \mathrm{dt}$ voltage. When multiplied by the appropriate constant, this became the voltage across the core. So the model sub circuit connects to the real circuit through two dependent voltage sources.

It is not possible to make a voltage source dependent on a function of another voltage source in the circuit in MCIV. But it is possible to make a variable resistor that varies as a function of another voltage in the circuit. So in order to make the function generators $f(B)$ and $g(B)$, I used a 1 amp current source and such a resistor.

I wanted to be able to control the value of $B$ at time equals zero. So to do this, I put a battery before the point in the circuit that is the $B$ voltage. To change the value of $B$ at time equals zero, all you have to do is change the voltage of this battery.

One of the most common problems encountered when running this model is that it just fails to run right from the beginning. I have often gotten very frustrated at the program because of this, only to eventually realize that this is because of a preference called Operating Point On. When the Operating Point is On, it will only give 
you the steady state output, and we want the transient output. If you run this model, or if you run any circuit with a capacitor charged to an initial condition, you must make sure that the Operating Point is turned OFF.

Another very common error is the simulation freezing up in the middle of a run. It will say "pivot too small" and stop. I think this is due to the numbers in the circuit either getting too big or too small. This problem can sometimes be avoided by changing the time step. For most runs, it can be set to 0 , and it will decide itself how big to make the time steps, and will run quickly. But when this pivot problem occurs, if you make the time step small enough, the simulation should run as far as you want. It will just take a really long time to get done. If you ever want to stop a run in the middle, hit apple - .. If you want to auto scale the range after a run, hit apple- d.

I just found another problem. I went back and tried to run my old simulations, and they all got stopped. I found out that the Global Settings had been changed. I put them back to the default settings, but things don't work the same as they did before. Before you could leave the time step on zero and it would run well. Now you can't do this. You have to put in a small number. I don't know what I had the Global Settings at before when I made the simulations, but you might be able to get it to run better if you play around with them. 


\section{Discussion of Future Work}

The Hodgdon model can display many of the characteristics of a real B-H curve. But it cannot simulate the initial peak due to the establishment of bar domains. (Carl Smith 1984) In an effort to do this, $f(B)$ and $g(B)$ were made from polynomial functions such that

$$
\begin{aligned}
& \left.f(B)\right|_{B}=\frac{1}{2}[h(\Delta)-h(-B)]+\frac{1}{2 \alpha}\left[\frac{d h(B)}{d B}-\frac{d h(\cdot B)}{d \theta}\right] \\
& \left.g(x)\right|_{j}=\frac{\alpha}{2}[h(x)+h(-x)]+\frac{1}{2}\left[\frac{\operatorname{ch}(x)}{d \theta}+\frac{d h(-x)}{d \theta}\right]
\end{aligned}
$$

where $h(B)$ and $-h(-B)$ are

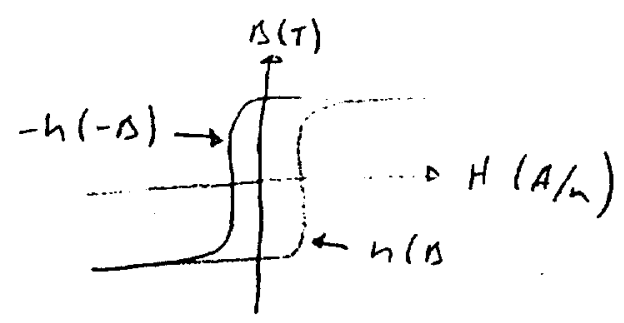

This $h(B)$ function was obtained by entering points on the curve into a spread sheet program that could then come up with a least squares polynomial (CricketGraph or Igor).

There are many problems with using these $f(B)$ and $g(B)$ functions though. One problem is getting a flat enough saturation line. The slope of polynomial fitted to data is always too steep in the saturation region. To take care of this, I made $f(B)$ and $g(B)$ piece wise polynomials. I don't know if the slope was shallow enough even then, because often the program would not be able to run past the transitions from one polynomial to another. 
Another small problem is centering a polynomial function. When you are entering the $\mathrm{B}-\mathrm{H}$ data to get a polynomial from the computer, you have to guess what the $\mathrm{B}$ is everywhere. This often causes the B-H loop to be off center.

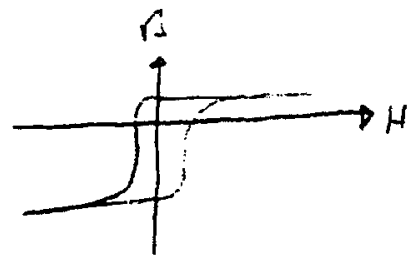

The interesting thing is that this does not affect its electrical characteristics. Current, which is proportional to $\mathrm{H}$ is not affected by an off center B. And voltage is proportional to $\mathrm{dB} / \mathrm{dt}$, which also is not affected by this skewed B. So this is only a problem in that it makes the B-H curve look wrong.

The real problem with this method is that it only works correctly if you start at one value of B. You can pick initial values of B that will have the curve go in the wrong direction. It messes up like this because no matter where $H$ is at, for a certain $B, H$ will move in the negative direction.

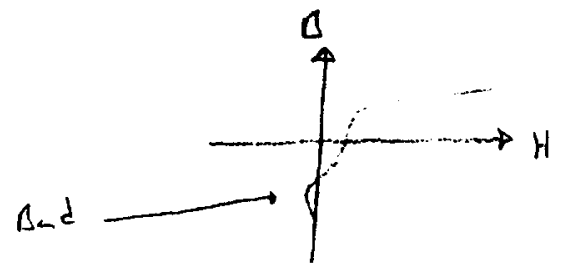

We would really like to have the $\mathrm{B}-\mathrm{H}$ loop make this bar domain peak. Finding a function that could do this and not make mistakes would be worthy of a paper.

An improvement would be to implement Hodgdon's suggested tangent functions. This would make a more realistic B-H curve.

The model takes up a lot of room in MCIV. It will be difficult to add it to any circuit but the most simple, because it is so big. Because of this, it would be useful if the whole model was turned 
into a Macro. Then just one element with the appropriate inputs could be used to represent the entire model.

Another improvement would be to divide the core up into segments, like Zentler did. This would account for uneven magnetization in the core and would hopefully produce a very realistic B-H curve.

The $c(d B / d t)$ function is just linear right now. This is not a very close approximation to the actual way the loss varries. A more complicated loss function should be found in order to make the loss more realistic.

\section{Appendix}

[1] E. C. Snelling, Soft Ferrites Properties and Applications, Butterworths, 1988, Boston.

[2] H. C. Kirbie, et al., "Development of Solid-State Induction Modulators for High PRF Accelerators", Proceedings of the 10th IEEE Pulsed Power Conference, Albuquerque, NM, July 10-13, 1995.

[3] Jan-Mark Zentler, "Modeling Tape-Wound Magnetic Switches", Proceedings of the 19th Power Modulator Symposium, June 26281990.

[4] B. D. Coleman, M. L. Hodgdon, "A Constitutive Relation for RateIndependent Hysteresis in Ferromagnetically Soft Materials", International Journal of Engineering Science, 24, No. 6, 1986, pp. 897-919. 
[5] B. D. Coleman, M. L. Hodgdon, "On a Class of Constitutive Relations for Ferromagnetic Hysteresis", Archives of Rational Mechanical Analysis, 99, No. 4, 1987, pp. 375-396.

[6] Marion L. Hodgdon, "Applications of a Theory of Ferromagnetic Hysteresis", IEEE Transactions, MAG-24, No. 1, 1988, pp.218221 .

[7] Marion L. Hodgdon, "Mathematical Theory and Calculations of Magnetic Hysteresis Curves", IEEE Transactions, MAG-24, No. 6, 1988, pp. 3120-3122.

[8] C. H. Smith, D. M. Nathasingh, "Magnetic Properties of Metallic Glasses under Fast Pulse Excitation", Proceedings of the 16th Power Modulator Symposium, June 18-20, 1984

[9] Personal communication with Smith, 1990, see attached sheet 


\section{DYNAMIC PULSE LOSSES METGLAS 2605SC ANNEALED \& REWOUND}

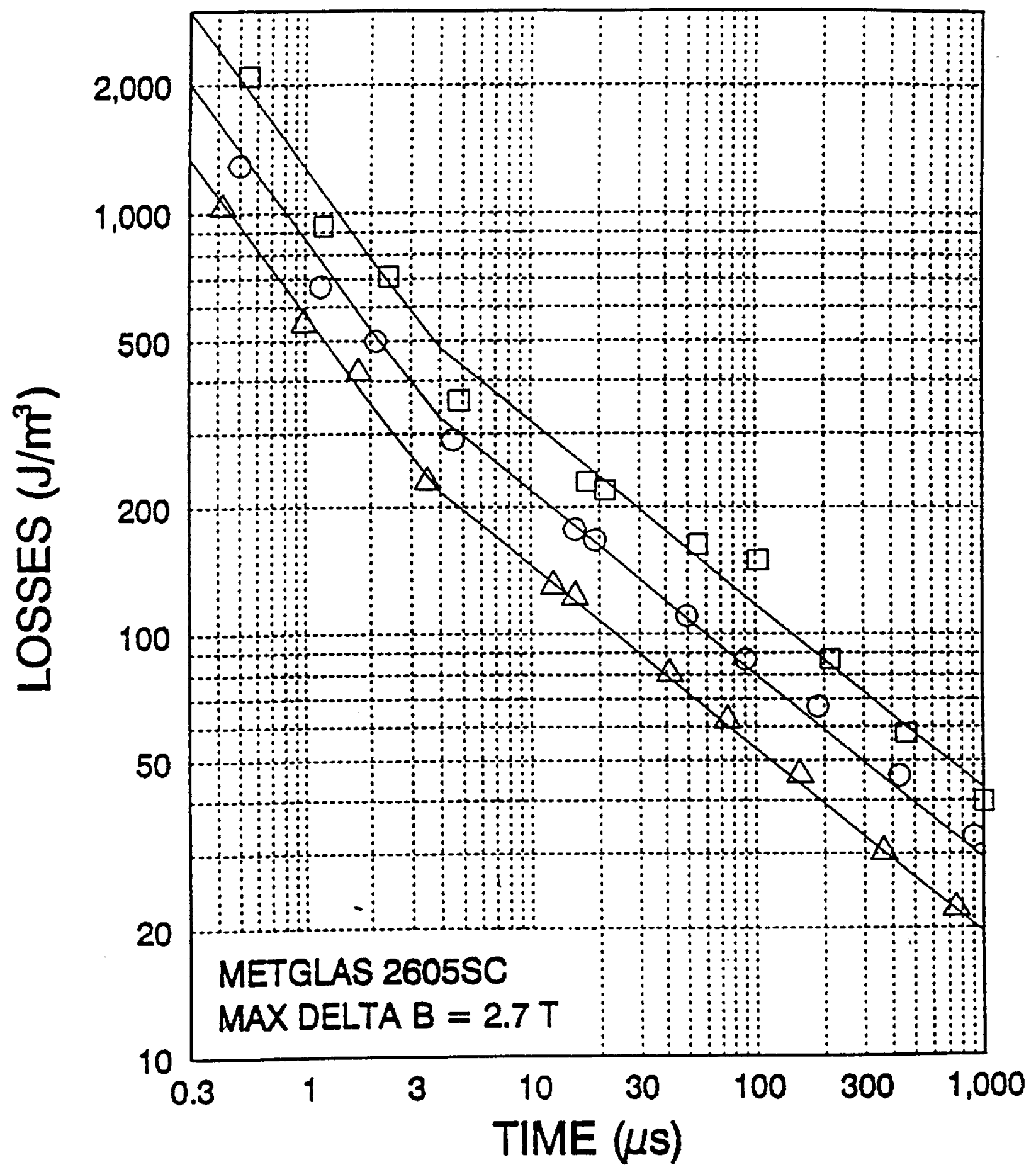

LOSSTO 2.0T LOSSTO 2.4T LOSS IN B-HLOOP $\triangle \quad$. 0 


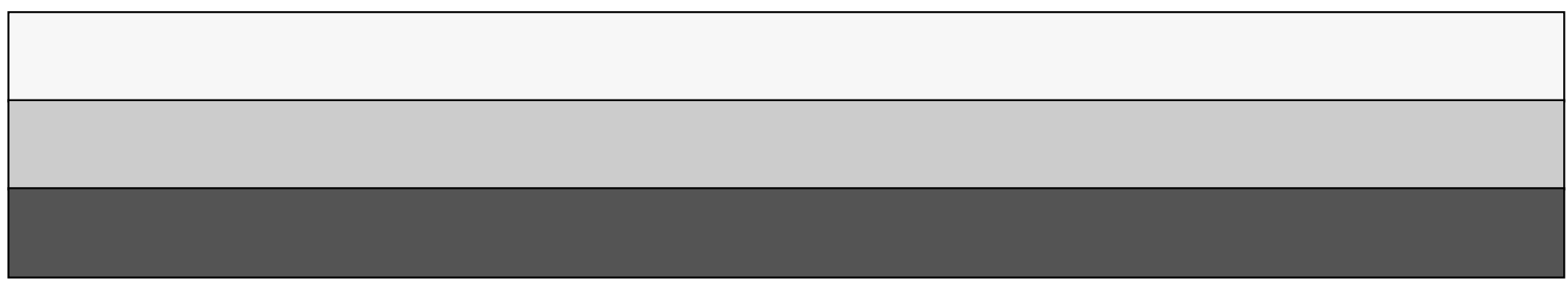

